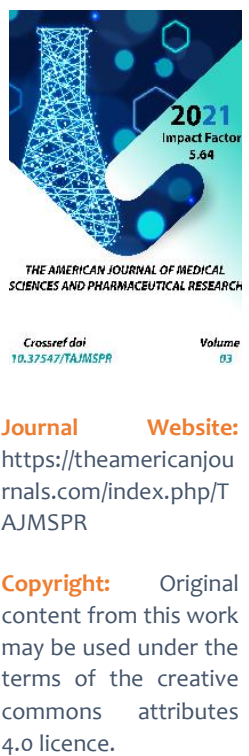

\section{Risk Of Pulmonary Artery Thrombosis In Type 2 DM Patients Hospitalized With Covid-19}

\author{
Nodirbek Ilkhomjon Ogli Yakubov \\ Assistant, Department Of Oncology And Medical Radiology, Andijan State Medical Institute, \\ Andijan, Uzbekistan \\ Dilfuzahon Zakirjanovna Mamarasulova \\ Md, Associate Professor, Head Of The Department Of Oncology And Medical Radiology, Andijan \\ State Medical Institute, Andijan, Uzbekistan \\ Nataliya Gamletovna Dadamyants \\ Ph.D., Senior Researcher, Republican Scientific Center For Emergency Medical Aid, Head Of \\ Department Of Ultrasound Diagnostics, Tashkent, Uzbekistan \\ Anvar Arabbayevich Dalimov \\ Doctor Of The Andijan Branch Of The Republican Specialized Medical Center For Emergency \\ Care, Uzbekistan
}

\title{
ABSTRACT
}

For the first time on the Fergana Valley model, prognostic markers of the risk of thrombotic complications in COVID-19 patients with type 2 diabetes were studied. It was found that the level of glycemia, the concentration of proinflammatory cytokines IL-6, ferritin and CRP, and the marker of thrombus formation - $d$ dimer, have a prognostic significance, with the maximum prognostic significance of the concentration of CRP. The prognostic significance of ultrasound in the aspect of thrombosis of the branches of the PA in patients with COVID-19 against the background of type 2 diabetes was established. Predictor markers are mean PA pressure, LV myocardial mass index, signs of increased intraventricular pressure in the RV, and evidence of peripheral venous thrombosis.

\section{KEYWORDS}

COVID-19, pulmonary artery thrombosis, type 2 DM.

\section{INTRODUCTION}

The new coronavirus infection COVID-19 is a new challenge to the global healthcare system, which in the first 7-8 months led to more than 10 million cases and more than 500 thousand deaths $[9,10]$. The complex pathogenetic cascade of the disease leads in severe cases to the development of interstitial pneumonia, progressing to acute respiratory distress syndrome (ARDS), sepsis and multiple organ failure [3]. The main risk factors for severe course, development of complications and mortality in patients with COVID-19 are old and 
senile age and obesity [6]. An important pathogenetic mechanism is hypercoagulation against the background of excessive activation of inflammation [3,4,7]. This position is confirmed by the detection of a high concentration of pro-inflammatory cytokines and markers and procoagulant markers, as well as a correlation between the concentration of interleukin-17 (IL-17) and fibrinogen [11]. Direct viral activation of the coagulation cascade is also not excluded. Coagulopathy includes sepsis-induced coagulopathy (SIC) and disseminated intravascular coagulation syndrome (DIC-s) with a tendency to hypercogulation and rare episodes of hemorrhage due to consumption coagulopathy [1]. Prothrombotic shifts in the coagulation system and thromboembolic events often complicate the clinical course of COVID-19, and are also often observed and cause death in patients with severe and extremely severe disease $[2,5]$. The mortality rate in this cohort of patients is 8-26\% [9]. Massive PE is the cause of death for three COVID-19 patients [1]. Thromboembolic events are recorded in $7.7-49 \%$ of patients with COVID$19[5,7,11]$, which is significantly higher than in patients without COVID-19.

\section{MATERIALS AND METHODS}

This study carried out on the model of the Fergana Valley. The study was conducted in two stages - retrospective and prospective and included 392 patients in whom COVID-19 developed against the background of type 2 diabetes, the study did not include patients on chronic anticoagulant therapy, as well as patients with atrial fibrillation and deep vein thrombophlebitis in history. patients on programmed hemodialysis, patients with malignant neoplasms.
The first stage of the study consisted in a retrospective comparison of case histories of two groups of type 2 diabetes patients who underwent COVID-19: patients who had pulmonary artery branch thrombosis during the infectious period of SARS-CoV2 infection (45 patients, group $T+$ ) and patients without thrombotic complications of SARS-CoV2 infection (45 patients, group T). Group $T$ was recruited according to the "case-control" principle: for each case history of the first group, a case history of a patient with the same volume of pulmonary parenchymal lesion and severity of infection and comparable age $( \pm 5$ years), but without thrombotic complications, was matched. Verification of the diagnosis "thrombosis of the branches of the pulmonary artery" was carried out according to the data of MSCT-angiopulmonography.

The second stage of the study was devoted to the study of the preventive efficacy of various therapy options in the aspect of thrombosis of the pulmonary artery branches. For this purpose, 3 groups of patients with diabetes mellitus 2 were formed, hospitalized in connection with COVID-19 of moderate, severe, and extremely severe degree, with a high risk of thrombosis of the branches of the pulmonary artery. All patients received the recommended therapy for COVID-19 associated interstitial pneumonia, including anticoagulant therapy. Patients of group P (102 patients) received rivaroxaban orally as an anticoagulant as part of therapy, at a dose of $20 \mathrm{mg} /$ day once; patients of group D (100 patients) - unfractionated heparin in the form of subcutaneous injections, four times a day (every 6 hours), the first dose - 5000 units (1 $\mathrm{ml}$ ), with subsequent dose adjustment depending on the APTT; patients of the LMWH group (100 patients) - low molecular weight 
heparin in the form of subcutaneous injections twice a day (every 12 hours) at a dose of $0.1 \mathrm{ml}$ per $10 \mathrm{~kg}$ of body weight each injection. The observation of patients lasted for 1 month, during which cases of thrombosis of the branches of the pulmonary artery were recorded in all compared groups. As a control group, 20 healthy volunteers of comparable age without signs of the pathology of the respiratory and cardiovascular systems were examined.

\section{RESULT AND DISCUSSION}

During the first stage, a retrospective comparison of patients with COVID-19, who developed against the background of diabetes mellitus 2 types, depending on the thrombosis of the branches of the LA. The groups were randomized according to the age of the patients, the severity of SARS-CoV2 infection, and the volume of lung tissue affected.

The study of some clinical features in patients with T2DM hospitalized for COVID-19, and distributed retrospectively depending on thrombosis of the pulmonary artery branches, revealed that thrombosis is associated with a longer duration of hospitalization ( $p<0.05)$, a longer period without anticoagulant therapy $(p$ $<0.01$ ), while the duration of the febrile period in the groups did not differ (Fig. 1).

The study of the predictor significance of the described clinical features of the infection did not reveal a significant change in the relative risk of thrombosis in patients with the duration of hospitalization and duration without an anticoagulant period above the median: for example, the duration of hospitalization more than 19.45 days was observed in 45 patients from whom thrombosis developed in 25 (55.56\% versus $44.44 \%$ in patients with a hospital stay of fewer than 19.45 days, chisquare $=1.16$, nd), duration without an anticoagulant period of more than 9.25 days was observed in 45 patients, of whom thrombosis developed in $26(57.78 \%$ versus $42.22 \%$ in patients with a shorter period without anticoagulant, chi-square $=2.22$, nd).

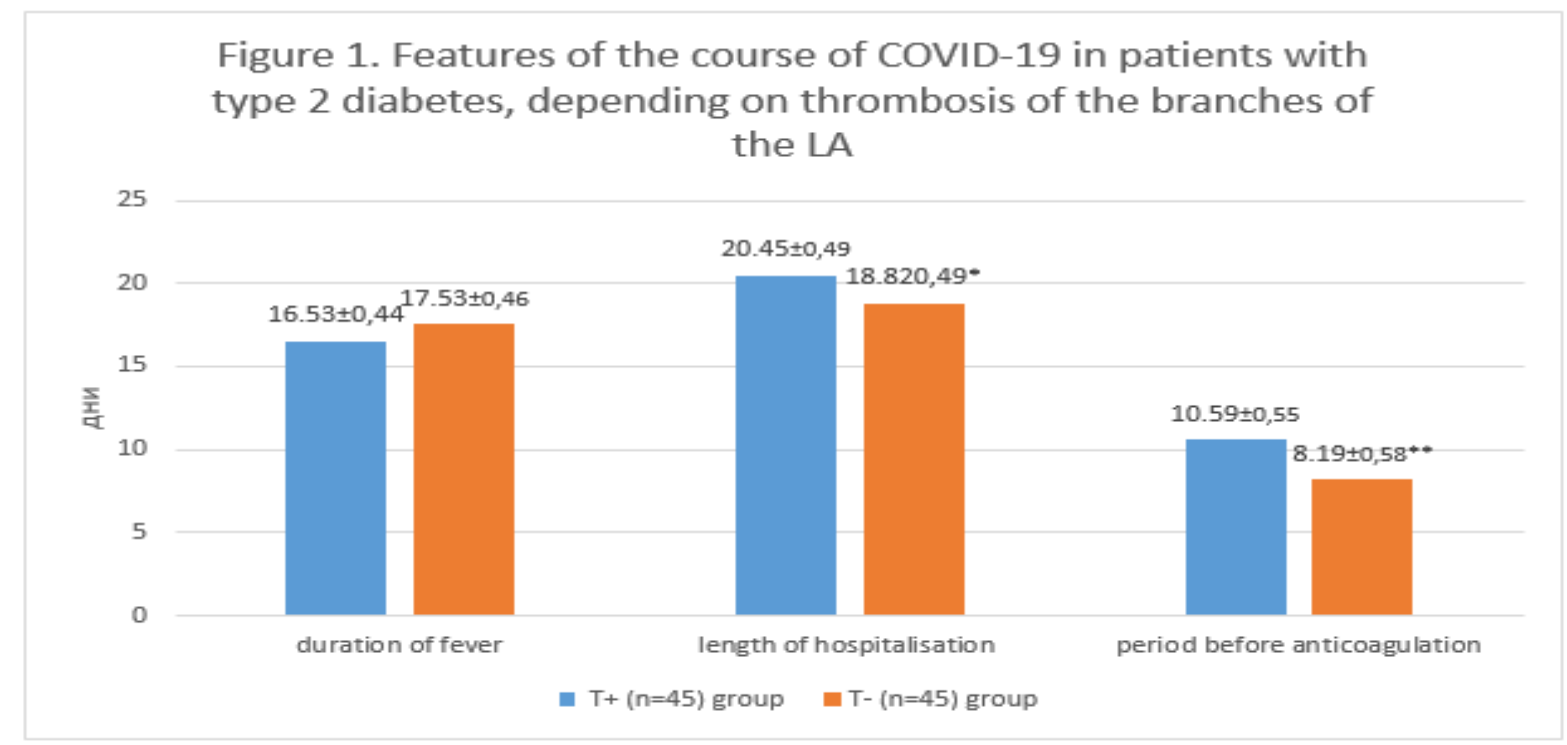

Note: * - reliability of intergroup differences: one sign - $p<0.05$, two signs - $p<0.01$. 
Thrombosis of the LA branches was associated with a higher level of glycemia upon admission to an infectious diseases hospital ( $p<0.001$, Table 1). The concentration of fibrinogen did not differ in patients depending on the development of thrombotic complications, which is probably due to the fact that fibrinogen is a marker of inflammation, not coagulation. Fibrinogen is produced by hepatocytes when stimulated by proinflammatory cytokines since its biological role is to create the basis of reparative scar tissue. A comparative study showed that in patients in whom COVID-19 was complicated by thrombosis of the branches of the pulmonary artery, markers of inflammation and thrombosis were significantly increased compared with patients without thrombotic complications (significance of intergroup

differences for all parameters - $\mathrm{p}<0.001)$. Correlation analysis found that the concentration of $\mathrm{D}$ dimer in the peripheral blood reliably and strongly correlates directly with the severity of glycemia $(r=0.76, p<0.01)$, and directly with the average strength - with the concentration of inflammatory markers such as ferritin $(r=0.59, p<0.01)$, IL-6 $(r=0.59$, $p<0.01)$ and $\operatorname{CRP}(r=0.62, p<0.01)$. This result confirms the hypothesis of inflammatory induction of thrombus formation in patients with viral interstitial pneumonia.

There are no significant relationships between the $\mathrm{D}$ dimer concentration and the duration of the febrile period ( $r=-0.03$, nd), without the anticoagulant period $(r=0.01$, nd), and the duration of hospitalization $(r=0.09$, nd) discovered.

Table 1

Comparative characteristics of type 2 diabetes patients hospitalized due to COVID-19, depending on the development of LA thrombosis

\begin{tabular}{|c|c|c|c|c|}
\hline Indicators & $\begin{array}{c}\mathrm{T}+(\mathrm{n}=45) \\
\text { group }\end{array}$ & $\mathrm{T}$ - $(\mathrm{n}=45)$ group & $\begin{array}{c}\text { Significance of } \\
\text { difference between } \\
\text { groups }\end{array}$ & median \\
\hline Glucose, $\mathrm{mmol} / \mathrm{I}$ & $9,81 \pm 0,45$ & $7,35 \pm 0,46$ & $\mathrm{P}<0,001$ & 8,15 \\
\hline Fibrinogen, g/l & $8,84 \pm 0,10$ & $9,02 \pm 0,10$ & HA & 8,95 \\
\hline d dimer, $\mathrm{mg} / \mathrm{I}$ & $4,76 \pm 0,33$ & $2,34 \pm 0,32$ & $\mathrm{P}<0,001$ & 2,70 \\
\hline Ferritin, $\mathrm{ng} / \mathrm{ml}$ & $1101,04 \pm 84,80$ & $628,56 \pm 81,70$ & $\mathrm{P}<0,001$ & 676,50 \\
\hline IL-6, $\mathrm{pg} / \mathrm{ml}$ & $84,00 \pm 6,09$ & $39,07 \pm 5,95$ & $\mathrm{P}<0,001$ & 45,00 \\
\hline CRP, $\mathrm{mg} / \mathrm{I}$ & $50,84 \pm 2,51$ & $28,20 \pm 2,36$ & $\mathrm{P}<0,001$ & 32,00 \\
\hline
\end{tabular}

Based on the data obtained, an analysis of the predictor significance in the aspect of thrombosis of the branches of the PA of laboratory markers was carried out, which 
significantly differed between the groups (Table 2). It was found that fasting glycemia upon admission to an infectious diseases hospital above $8.15 \mathrm{mmol} / \mathrm{I}$ is associated with an increase in the relative risk of thrombosis of the branches of the pulmonary artery by almost 2.5 times ( $p<0.001)$, an increase in the concentration of D-dimer above $2.7 \mathrm{mg} / \mathrm{I}$, ferritin above $676.5 \mathrm{ng} / \mathrm{ml}$ and IL-6 above 45 $\mathrm{pg} / \mathrm{ml}$ - by 3.23, 2.45 and 3.23 times, respectively ( $\mathrm{p}<0.001$ for all three markers), and the highest predictor significance was demonstrated by the concentration of CRP - an increase in the level of more $32 \mathrm{mg} / \mathrm{L}$, increases the relative risk of thrombosis by 6.2 times $(p<0.001)$.

Table 2

Predictive significance of laboratory markers of inflammation and thrombosis in patients with T2DM hospitalized for SARS-CoV2 infection in terms of the risk of developing thrombosis of the pulmonary artery branches

\begin{tabular}{|c|c|c|c|c|c|}
\hline Indicator & $\begin{array}{l}\text { Predictor } \\
\text { (median) }\end{array}$ & $\begin{array}{c}\text { Frequency of } \\
\text { adverse events in } \\
\text { patients in the } \\
\text { presence of a } \\
\text { predictor, number of } \\
\text { events/number of } \\
\text { persons with a } \\
\text { predictor (\%) }\end{array}$ & $\begin{array}{c}\text { Frequency of } \\
\text { adverse events in } \\
\text { patients without a } \\
\text { predictor, number of } \\
\text { events/number of } \\
\text { persons without a } \\
\text { predictor (\%) }\end{array}$ & $\begin{array}{c}\text { Chi- } \\
\text { square }\end{array}$ & $\begin{array}{c}\text { OR of } \\
\text { events in } \\
\text { presence of } \\
\text { a predictor }\end{array}$ \\
\hline $\begin{array}{c}\text { Glycemia, } \\
\mathrm{mmol} / \mathrm{L}\end{array}$ & $>8,15$ & $32 / 45(71,11 \%)$ & $13 / 45(28,89 \%)$ & $16,09 * * *$ & 2,46 \\
\hline $\begin{array}{c}\text { d dimer, } \\
\text { mg / L }\end{array}$ & $>2,70$ & $34 / 44$ & $11 / 46$ & $25,66 * * *$ & 3,23 \\
\hline $\begin{array}{l}\text { Ferritin, ng } \\
\qquad / \mathrm{ml}\end{array}$ & $>676,50$ & $32 / 45$ & $13 / 45$ & $16,09 * * *$ & 2,46 \\
\hline $\mathrm{L}-6, \mathrm{pg} / \mathrm{ml}$ & $>45,00$ & $34 / 44$ & $11 / 46$ & $25,66 * * *$ & 3,23 \\
\hline CRP, mg/l & $>32,00$ & $38 / 42$ & $7 / 48$ & $51,65^{* * *}$ & 6,20 \\
\hline
\end{tabular}

Note: * - reliability of the chi square test: three signs - $p<0.001$ 


\section{CONCLUSIONS}

1. The death rate in patients with COVID-19 against the background of type 2 diabetes with a high risk of thrombotic events is $34 \%$, which is 2.72 times higher than in patients with a low risk of thrombotic complications. The developed combined scale for assessing the risk of thrombotic events in patients with COVID-19 against the background of type 2 diabetes has a predictive sensitivity in relation to the risk of hospital mortality $77.72 \%$, specificity $51.47 \%$, predictive efficiency $-57.78 \%$. The use of long-term anticoagulant therapy reduces the risk of hospital death by 2.44 times (up to $13.91 \%$ ).

2. The introduction of long-term anticoagulant therapy into the therapy regimen for patients with COVID-19 against the background of type 2 diabetes, with a high risk of thrombotic events, can reduce the risk of thrombosis of the branches of the LA: the use of rivaroxaban $20 \mathrm{mg}$ per day from $82 \%$ to $65.69 \%$ (chi-square $=4.49$, p <0.05), subcutaneous heparin every 6 hours at a dose administered until the target APTT level is reached up to $64 \%$ (chisquare $=5.29, \mathrm{p}<0.01)$, low molecular weight heparin at a dose of $0.1 \mathrm{ml} / 10 \mathrm{~kg} \mathrm{~s} /$ c every 12 hours up to $49 \%$ (chi-square = 15.25, $\mathrm{p}$ <0.001). Low molecular weight heparin therapy (chi-square $(2 \times 3)=7.04, p$ $<0.05$ ) has the highest preventive efficacy in terms of thrombotic events compared with rivaroxaban and unfractionated heparin.

3. The use of long-term anticoagulant therapy contributes to a significant decrease in the concentration of $D$ dimer in the peripheral blood with the most pronounced effect of low molecular weight heparin (decrease by $53.75 \%, p<0.001$ with the initial data, $p$ $<0.05$ reliability of the difference in relative dynamics with the rivaroxaban and unfractionated heparin groups) compared with rivaroxaban $(27.53 \%$ decrease, $p$ $<0.001)$ and unfractionated heparin $(23.12 \%$ decrease, $p<0.001$ )

\section{REFERENCES}

1. Ackermann $M$, Verleden SE, Kuehnel $M$, et al. Pulmonary vascular endothelialitis, thrombosis, and angiogenesis in COVID19.// N Engl J Med .-2020.-383(2).-120-128.

2. Al-Samkari H, Karp Leaf RS, Dzik WH, et al. COVID-19 and coagulation: bleeding and thrombotic manifestations of SARSCoV-2 infection.// Blood .-2020.-136(4).489-500.

3. American Society of Hematology. COVID19 and VTE/anticoagulation: frequently asked questions. Available from: https://www.hematology.org/covid19/covid-19-and-vte-anticoagulation.

Accessed 13 June 2020.

4. Buonsenso D, Raffaelli F, Tamburrini E, Biasucci DG, et al. Clinical role of lung ultrasound for the diagnosis and monitoring of COVID-19 pneumonia in pregnant women. //Ultrasound Obstet Gynecol. -2020.

5. Carestia A, Frechtel G, Cerrone G, et al. NETosis before and after hyperglycemic control in type 2 diabetes mellitus patients.// Plos One.- 2016.-11(12).e0168647.

6. Cariou B, Hadjadj S, Wargny $M$, et al. CORONADO Investigators. Phenotypic 
characteristics and prognosis of inpatients with COVID-19 and diabetes: the CORONADO study. //Diabetologia. -2020.63(8).-1500-1515.

7. Fraissé $M$, Logre E, Pajot $\mathrm{O}$, Mentec $\mathrm{H}$, et al. Thrombotic and hemorrhagic events in critically ill COVID-19 patients: a French monocenter retrospective study. //Crit Care.- 2020.-24(1).-275.

8. Gervaise A, Bouzad C, et al. Acute pulmonary embolism in non-hospitalized COVID-19 patients referred to CTPA by emergency department.// Eur Radiol.- 2020.-30(11).-6170-6177.

9. Girard P, Sanchez O, Leroyer C, et al. Deep venous thrombosis in patients with acute pulmonary embolism: prevalence, risk factors, and clinical significance.// Chest.- 2005.-128(3).-15931600.

10. Han H, Yang L, Liu R, Liu F, et al. Prominent changes in blood coagulation of patients with SARS-CoV-2 infection. //Clin Chem Lab Med. -2020.

11. Hardaway RM, Williams $\mathrm{CH}$, Marvasti $\mathrm{M}$, et al. Prevention of adult respiratory distress syndrome with plasminogen activator in pigs. //Crit Care Med. -1990.-18.-413-1418. 